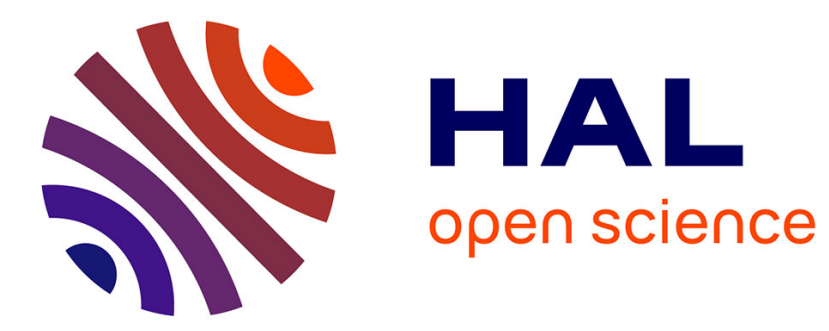

\title{
The shrinkage of oak predicted from its anatomical pattern: validation of a cognitive model
}

\author{
Eric Badel, Patrick Perre
}

\section{To cite this version:}

Eric Badel, Patrick Perre. The shrinkage of oak predicted from its anatomical pattern: validation of a cognitive model. Trees - Structure and Function, 2007, 21 (1), pp.111-120. 10.1007/s00468-0060105-z . hal-01189257

\author{
HAL Id: hal-01189257 \\ https://hal.science/hal-01189257
}

Submitted on 18 Feb 2019

HAL is a multi-disciplinary open access archive for the deposit and dissemination of scientific research documents, whether they are published or not. The documents may come from teaching and research institutions in France or abroad, or from public or private research centers.
L'archive ouverte pluridisciplinaire HAL, est destinée au dépôt et à la diffusion de documents scientifiques de niveau recherche, publiés ou non, émanant des établissements d'enseignement et de recherche français ou étrangers, des laboratoires publics ou privés. 


\title{
The shrinkage of oak predicted from its anatomical pattern: validation of a cognitive model
}

\author{
Eric Badel · P. Perré
}

\begin{abstract}
This paper deals with the ability of a scientific strategy to compute the shrinkage behaviour of any oak sample, regardless of its origin, density, growth ring, etc. This approach uses the description of the actual oak structure at the annual ring level (i.e. the spatial organisation of the radial ray-cells, fibre, parenchyma areas and large vessels), to evaluate its shrinkage/swelling and elastic properties in the transverse directions. For the shrinkage properties, computed results were compared with experimental values measured on a set of samples depicting a very large diversity of anatomical patterns. The accuracy of our prediction is about $5 \%$ in the tangential direction and $20 \%$ in the radial direction, which is much better than statistical models over a wide range of variables. These results are discussed and a few microscopic observations with ESEM allow explanation of anomaly points of behaviour to be formulated. Such good results could allow this approach to be used to study the influence of growing conditions or of global changes upon physical wood properties.
\end{abstract}

Keywords Modelling - Morphology-based - Anatomy · Swelling · Shrinkage · Wood · Oak · Cognitive

\section{Introduction}

Building a model that is able to predict wood properties is a common goal of many scientists who try to address different demands. Some of these demands come from industry and are focused on the optimised use of the raw material they have to transform (Seco and Barra 1996). Others try to establish relationship between growth conditions, anatomy, stand characteristics and the physical properties of wood (Berges et al. 2000; Beismann et al. 2002; Woodcock 2002). Because of it technical importance in the use of wood products, shrinkage, especially in the transverse directions, has been paid close attention for decades. Shrinkage experiments are time consuming. Therefore, the main objectives of modelling works are focused on the possibility of predicting these properties. Literature shows several ways to investigate this problematic theme. On the one hand, huge experimental data describe a forestry resource (Eyono Owoundi 1992; Zhang and Nepveu 1994; Le Moguedec 2000). Thanks to these data, macroscopic parameters (annual ring width, cambial age, position in the trunk, etc) can be used as inputs for statistical models that estimate the mean properties of the resource and its variability. These models can be useful at the stand of the forest level. But they are not relevant to estimate the properties of one individual wood sample (Badel et al. 2006). On the other hand, cognitive studies try to formulate, and to understand and simulate the relationship between the structure of the material and its properties. For gymnosperms that have a simple anatomical structure, the variations inside the annual-ring width are almost only along the radius. This is why specific attention has been focused on the effect of the cell arrangement on the local properties. The microscopic structure of cells (organisation of the multilayers, microfibril angle of the cell wall), their shape (spatial organisation of the cells) or their chemical compositions, (Salmen 2004), are 
commonly involved in the transverse shrinkage and/or mechanical properties. For 40 years, several theoretical models have been elaborated (Barber 1968; Koponen et al. 1989; Farruggia 1998; Watanabe et al. 1998; Holmberg et al. 1999; Yamamoto 1999; Gu et al. 2001; Yamamoto et al. 2001; Pang 2002; Perré 2002).

For angiosperms, and especially for ring-porous species like oak, anatomical structure varies in both radial and tangential directions and the complex two-dimensional (2-D) interaction that exists at the ring-width level between the different tissues is of great importance. Except for numerous work dealing with the effect of ray cells on the transverse anisotropy of angiosperms (Keller and Thiercelin 1975; Kawamura 1979, 1984; Burgert et al. 2001), few studies have been performed to investigate the properties of such materials. A mechanical model has been proposed by Guitard and El Amri (El Amri 1987) to understand the elastic properties of oak. In the formulation, the proportion and a schematic arrangement of the tissues (in parallel or in series) only have been taken into account. Clair et al. (2003) studied the effect of tension wood upon shrinkage and mechanical behaviour for chestnut at the annual ring level.

Yet, in the case of oak wood, the heterogeneity at the annual-ring level called for an explanation at this tissue level. This paper is the culmination of a whole modelling work. For several years, we have been presenting the different elements of a complete modelling tool chain. In two previous papers, (Badel and Perré 2002; Perré and Badel 2003), we described a modelling tool that is able to predict the shrinkage/swelling and the elastic properties of oak wood in the transverse directions. This model is based on the description of the actual anatomical structure of the annual ring and takes the microscopic properties of each tissue into account (Badel and Perré 1999, 2001). The validity of this theoretical approach should be tested by comparison with experiments.

In order to validate this chain of predicting tools, a wide range of anatomical patterns was selected from samples coming from 288 oak trees. Swelling experiments have been performed on microsamples prepared from the selected anatomical patterns. Then, the modelling tool chain has been applied, starting from X-ray images of these samples. Based on these results, the objective of this paper is the experimental validation of the cognitive model: the evaluation of its ability to really predict the swelling properties of any oak sample is discussed.

\section{Method}

The modelling principles

The modelling tool chain has been detailed in previous papers (Badel and Perré 2002; Perré and Badel 2003). The main principles are summarised as follows. The deterministic approach uses the techniques of composite material sciences. Assuming that the local properties of each component and their spatial distribution are known, homogenisation techniques allow the macroscopic properties of the heterogeneous material to be computed. The mathematical formulation leads to the following equation (Sanchez-Huber and Sanchez-Palencia 1992) that makes a distinction between two separate terms:

$$
\begin{aligned}
& \underset{\text { genised Values }}{A_{i j k h}}=\frac{\left\langle a_{i j k h}\right\rangle}{\text { Average of the microscopic values }} \\
& \text { Homogenised Values Average of the microscopic values } \\
& +\underset{\text { Corrective term }}{\left\langle a_{i j l m} e_{y l m}\left(X^{k h}\right)\right\rangle}
\end{aligned}
$$

This equation tells us that the macroscopic property is the sum of the average of the microscopic properties plus a second term, called "the corrective term", which represents the effect of the microscopic morphology, i.e. the spatial organisation of the components withing the unit cell.

In practical terms, for oak wood, this approach involves the characterisation of two types of data (Fig. 1):

- The local (or "microscopic") properties of each tissue,

- The description of the morphology of the anatomical structure of the annual ring.

The first sets of data have been experimentally determined with the help of specific devices:

- Tensile tests under microscope allowed the individual mechanical properties (elastic Young modulus and Poisson's ratio) of fibre zones, ray cells and parenchyma cells to be measured; both in radial and tangential directions (Badel and Perré 1999).

- The comparison of images collected by a digital X-ray imaging device at different relative humidity conditions, allowed the swelling coefficients of these same tissues to be evaluated (Badel and Perré 2001).

On the other hand, X-ray images of the transversal structure are used to describe the structure of the annual ring and to separate the diverse tissues. MeshPore, a software tool developed in LERMAB (Perré 2005), allows the boundaries of the tissues area to be described using image segmentation and description of contours by segment chains. In this way, we define the four types of tissues: radial ray-cells, fibre, parenchyma areas and large vessels. This new vector-valued information becomes the input data of freeware mesh generator $\left(\right.$ Easymesh $\left.^{(\mathrm{c})}\right)$ that builds a Finite Element mesh. Triangular elements are chosen to follow the complex shapes of the tissues. The refinement of the description is totally controlled by MeshPore to ensure the most realistic description of the true anatomi- 


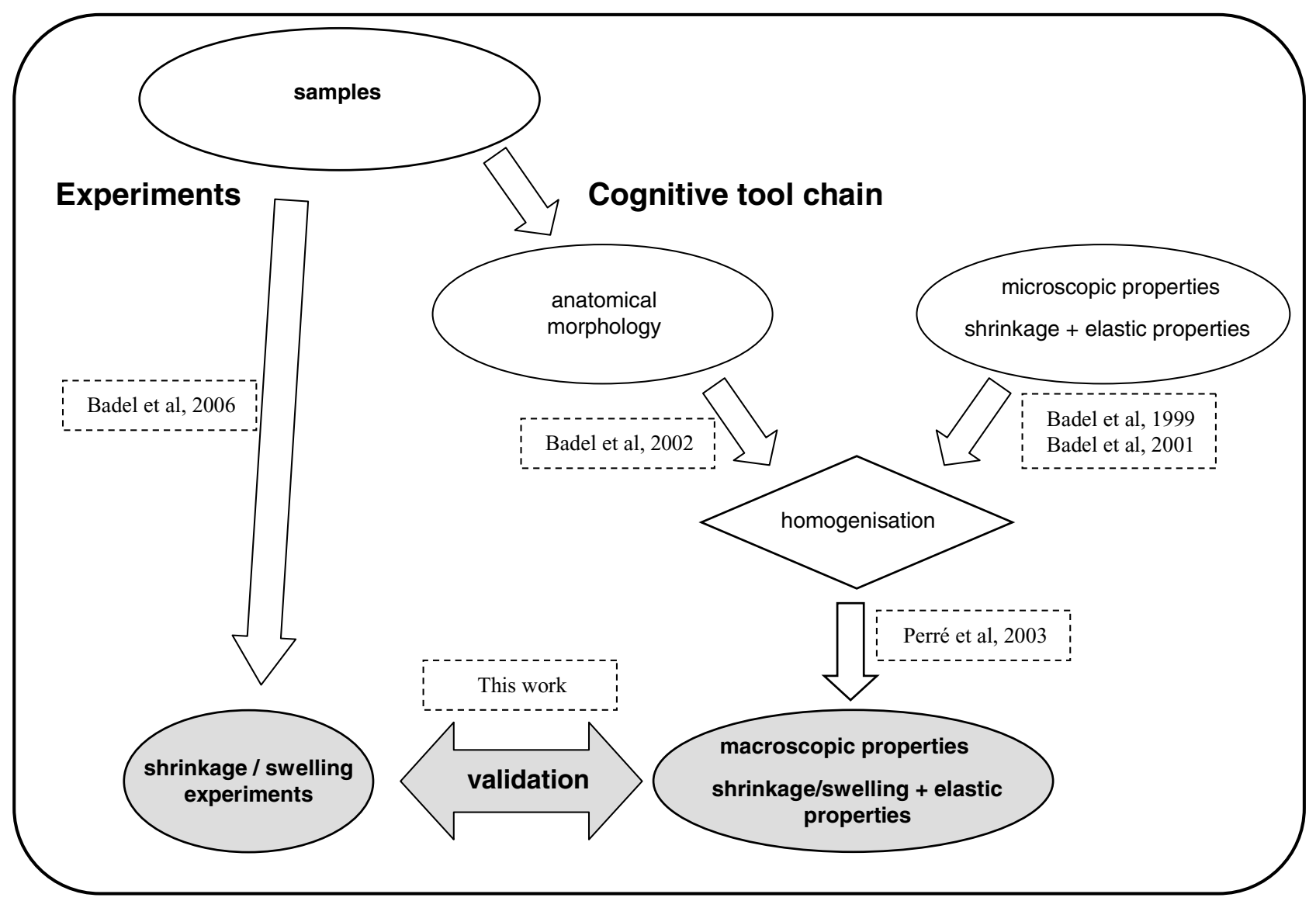

Fig. 1 Principle of homogenisation: this paper is devoted to the experimental validation of the cognitive model

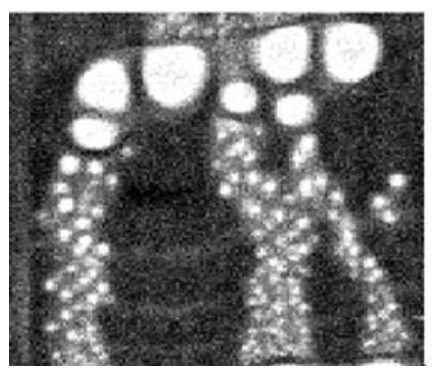

Fig. 2 From the X-ray image information to the Finite Element mesh. MeshPore provides a vector-valued description of the tissues boundaries. Then, Easymesh generates the triangular Finite Element Mesh.

cal oak structure. Figure 2 depicts the main steps of this procedure.

Finally, MorphoPore, a software tool also developed in LERMAB, reads the mesh, attributes the individual properties of the tissues (Table 1) and computes the macro-
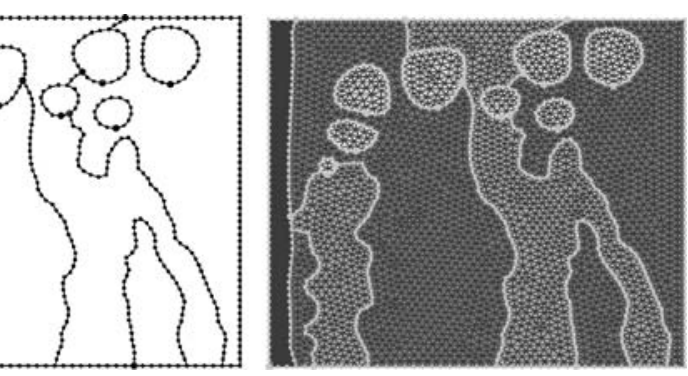

It describes the material as a composite made of big vessels, ray cells, parenchyma and fibre zones as close as possible to the actual structure

scopic properties of the heterogeneous structure, i.e. the swelling/shrinkage and the elastic mechanical properties in the radial and tangential directions.
Table 1 Individual properties of each component of the annual ring $^{a}$

${ }^{a}$ Elastic properties and swelling coefficients.

\begin{tabular}{lllllll}
\hline & $E_{\mathrm{R}}(\mathrm{MPa})$ & $E_{\mathrm{T}}(\mathrm{MPa})$ & $\nu_{\mathrm{TR}}$ & $G_{\mathrm{TR}}$ & $\alpha_{\mathrm{R}}(\% / \%)$ & $\alpha_{\mathrm{T}}(\% / \%)$ \\
\hline Vessels & 1 & 1 & 0.10 & 0.45 & 0 & 0 \\
Parenchyma & 1700 & 850 & 0.40 & 607 & 0.142 & 0.253 \\
Fibre & 1900 & 1900 & 0.71 & 555 & 0.334 & 0.553 \\
Rays cells & 3600 & 3800 & 0.30 & 1385 & 0.167 & 0.177 \\
\hline
\end{tabular}


The experimental protocol

Assuming that the anatomical morphology of wood is the result of the genetic origin and of the growth conditions of the tree, the ultimate ambition of our model is to predict the behaviour of any oak sample without the knowledge of the forest of origin, the age, the species (Quercus robur or petraea), the density, etc. The sampling has been chosen to be as representative as possible of the anatomical variability one could observe in a huge database of 37,000 annual rings coming from 288 oak trees from eight forests scattered across France (Bakour 2003; Badel et al. 2006). The annual ring width, the density (measured on X-ray micrographs) and the species have been combined to select 12 samples, which include typical and untypical samples (i.e. large annual ring with low density or the contrary).

The predicting formulation computes the behaviour of a material made of a periodic repetition of the same annual ring pattern. This led us to select only steady growth zones made up of three similar annual rings in the radial direction and three or four zones between large rays in the tangential direction. Moreover, the model is a 2-sD approach. The cutting to shape of the sample (only $1 \mathrm{~mm}$ thick in the longitudinal direction, radial-tangential plane perpendicular to the spiral grain, etc) was carefully done to be in accordance with the model's hypothesis.

The 12 samples were all placed inside a digital X-ray imaging system at the same time. This device was designed to control the dry bulb temperature and the relative humidity of the air surrounding the samples. The accuracy and the stability of the device have been tested over several weeks. The stability of the dry temperature was characterised by a standard deviation equal to $\pm 0.038^{\circ} \mathrm{C}$, with a maximum value of $0.28^{\circ} \mathrm{C}$ peak-to-peak. The stability of the relative humidity was $\pm 1 \%$; the latter was measured using a capacity sensor calibrated with the aid of a dew point analyser. Five hygrometric steps were performed along a sorption cycle and a desorption cycle. Each step was long enough for the equilibrium state to be reached. At the end of each step, an X-ray image of each sample was recorded. Finally, an image correlation process based on the grey level distribution of the whole image compared the different records to determine the strain field due to shrinkage or swelling. The swelling coefficient is defined as the slope of the strain curve plotted against relative humidity. Because the algorithm is based on images, these swelling coefficients are extracted simultaneously in radial and tangential directions (Badel et al. 2006). Let us note that the samples were initially already air dried before the experiments. So, the hysteresis of the first drying is removed. Moreover, in this range of relative humidity, we assume that the behaviour between shrinkage and swelling is more or less similar. To free the confusion between the two terms, the same calculation is performed for both the steps and the definition of the swelling coefficient is used for swelling and shrinkage stages.

\section{Results and discussion}

During the computation of the properties, the software (MorphoPore) imposes periodic displacements over the calculation domain in the radial and tangential directions (Fig. 3). In order to reduce the computational procedure (image segmentation, FE mesh generation, computational time), only the central annual ring of the sample was used to represent the periodic structure. Because we have chosen samples with regular anatomical patterns, it is important to notice that this procedure perfectly matches the above mentioned hypothesis of periodic conditions. The computed part of the image is called the "Representative Elementary Volume" (R.E.V.). This R.E.V. is physically linked to neighbouring parts of the sample. According to this configuration, the shrinkage (swelling) of the entire sample is macroscopically free while the shrinkage (swelling) of the R.E.V. is constrained by its similar neighbouring parts. Figures 4 and 5 depict the R.E.V. and the boundary representation of each sample.

The calculations were performed for the 12 samples. The computed swelling coefficients are listed in Table 2 and are compared to the experimental values. The gap between com-

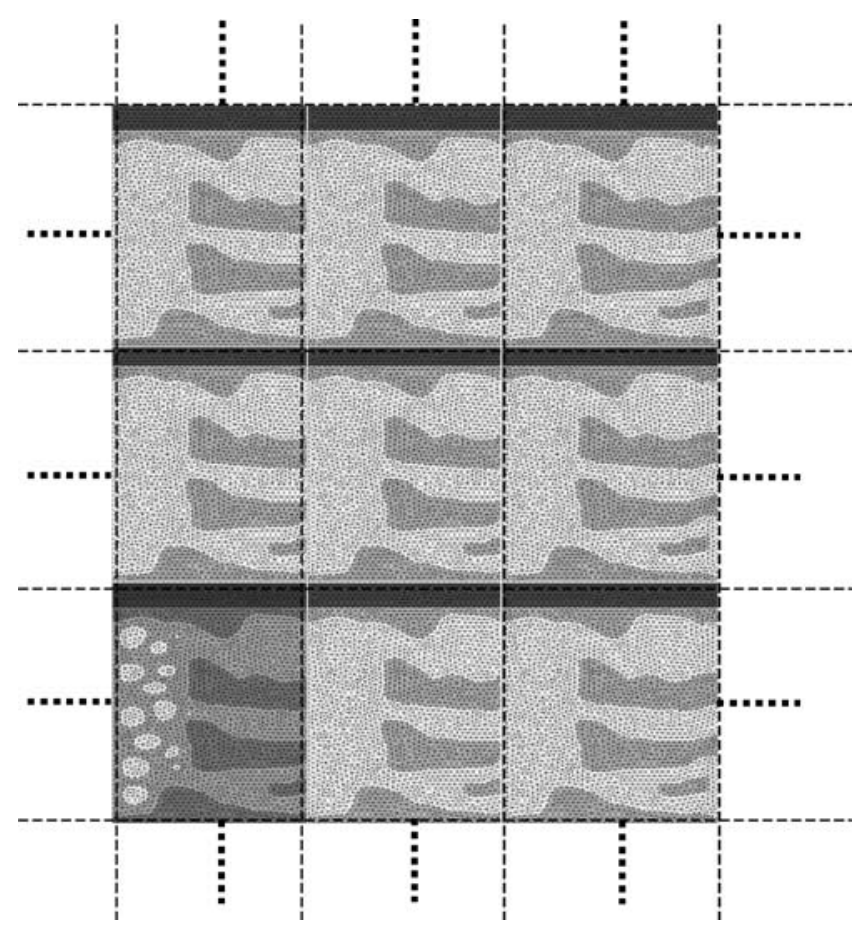

Fig. 3 Homogenisation concept applied to the anatomical structure of oak. The annual ring is the Representative Elementary Volume of a periodic material 
Fig. 4 X-ray image of samples 1 to 6 , Representative Elementary Volume (R.E.V.) and contour chains resulting from image segmentation. The computation of the macroscopic properties is performed using triangular Finite Element meshes generated from these contours

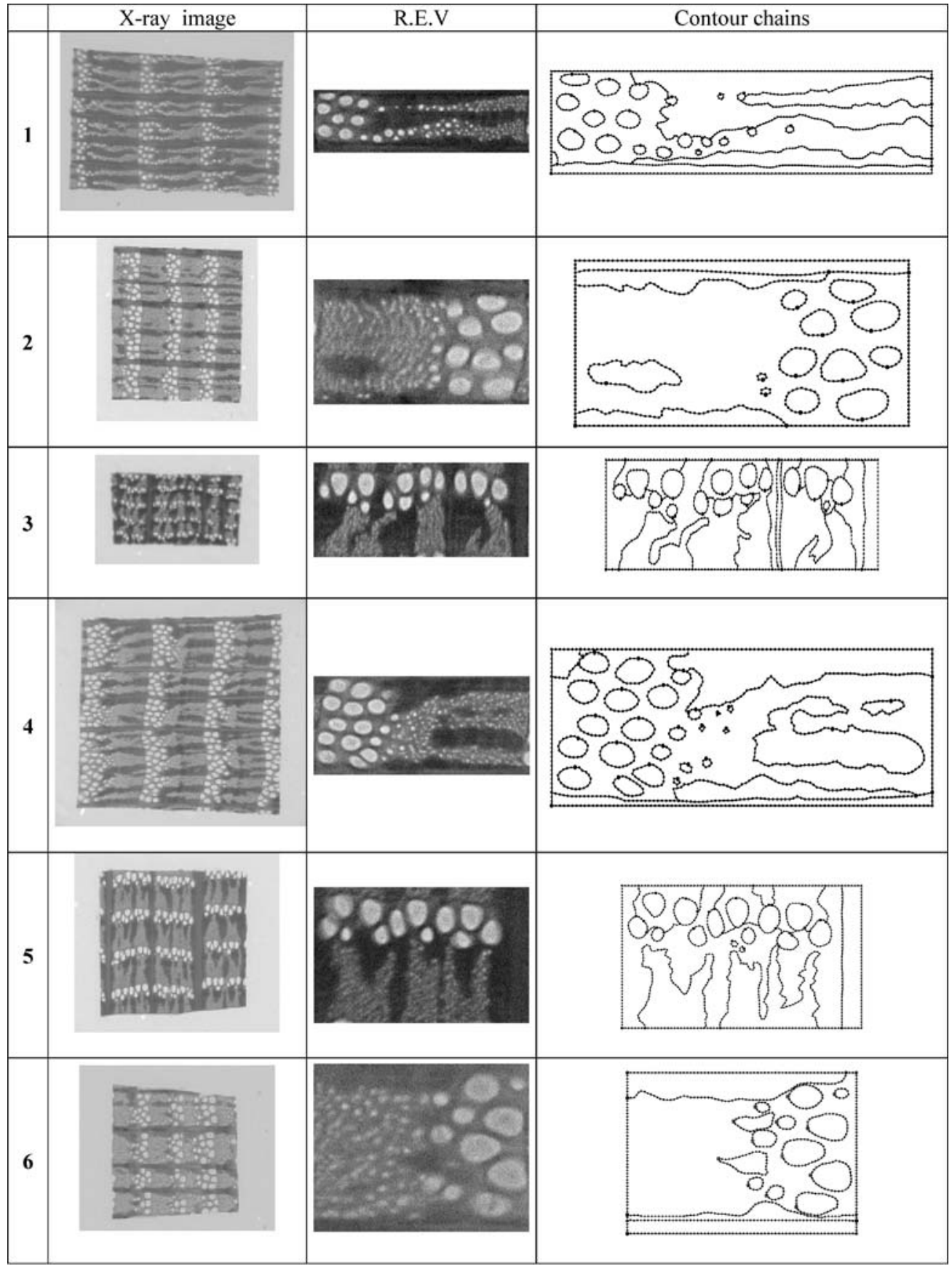

puted and experimental values can be quantified for each sample as follows:

$\operatorname{error}(\%)=\frac{\mid \text { computed }- \text { experimental } \mid}{\text { experimental }}$

In both directions, the evaluation is quite good. For the first time, a cognitive modelling chain is able to predict the swelling behaviour of oak in radial and tangential directions with an acceptable accuracy; without any information concerning the origin and/or the history of the sample (age, from the pith or from the bark, position in the trunk, etc.). These results exhibit four comments:

- The large natural variability of property that can be observed with the experimental data is clearly reproduced by the predictive model.

- The computed values fit well with the experimental values. The average error is only $9.4 \%$ in the tangential direction.

- Although the prediction is not as good in the radial direction, the average error remains acceptable (error: $21.9 \%$ ), 
Fig. 5 X-ray image of samples 7 to 12 , Representative Elementary Volume (R.E.V.) and contour chains resulting from image segmentation. The computation of the macroscopic properties is performed using triangular Finite Element meshes generated from these contours

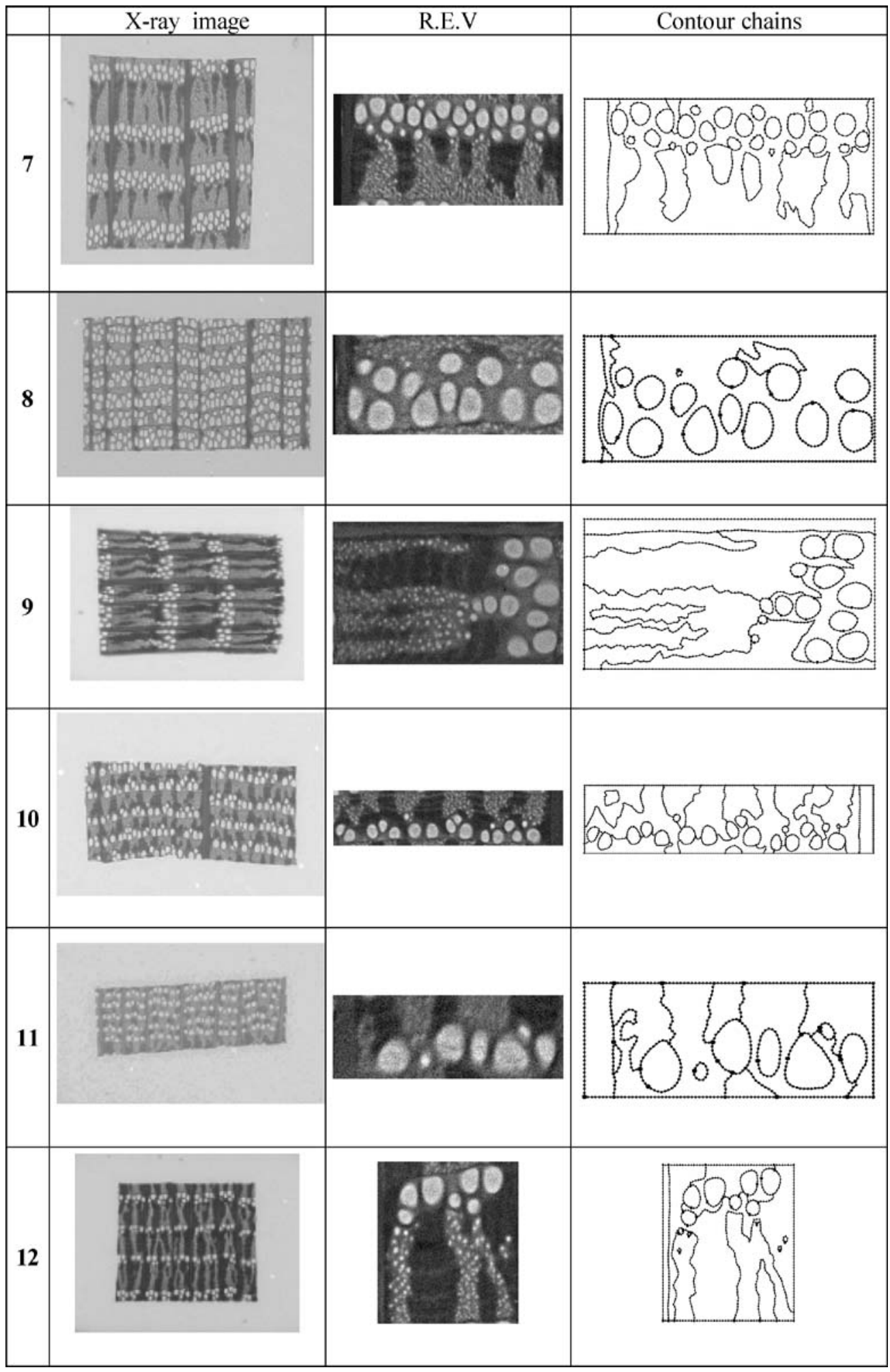

- In both cases, the model overevaluates the shrinkage coefficients.

At this stage, it is necessary to stipulate that to obtain accurate results, the model must represent the anatomical structure of the sample as closely as possible. A previous study about the sensibility of the model showed the significant role of ray cells (Badel 1999). Keeping in mind that the REV used in this work contains only one large ray cell, it becomes obvious that a bad description of this element can 
Table 2 Swelling coefficients ${ }^{a}$

\begin{tabular}{llllll}
\hline \multirow{2}{*}{ Sample } & \multicolumn{2}{l}{ Experimental data } & \multicolumn{2}{l}{ Predicted values } \\
\cline { 2 - 3 } & $\alpha_{\mathrm{R}}(\% / \%)$ & $\alpha_{\mathrm{T}}(\% / \%)$ & & $\alpha_{\mathrm{R}}(\% / \%)$ & $\alpha_{\mathrm{T}}(\% / \%)$ \\
\hline 1 & 0.198 & 0.357 & 0.216 & 0.376 \\
2 & 0.104 & 0.32 & 0.171 & 0.297 \\
3 & 0.258 & 0.44 & 0.243 & 0.420 \\
4 & 0.199 & 0.377 & 0.200 & 0.377 \\
5 & 0.253 & 0.396 & 0.221 & 0.402 \\
6 & 0.155 & 0.29 & 0.192 & 0.300 \\
7 & 0.147 & 0.323 & 0.205 & 0.400 \\
8 & 0.139 & 0.231 & 0.166 & 0.308 \\
9 & 0.183 & 0.366 & 0.228 & 0.394 \\
10 & 0.228 & 0.386 & 0.242 & 0.411 \\
11 & 0.243 & 0.372 & 0.201 & 0.377 \\
12 & 0.191 & 0.382 & 0.266 & 0.453 \\
\hline
\end{tabular}

${ }^{a}$ Confrontation of predicted values with experimental data. Raw data: first computation.

affect the computed result. In order to increase the quality of the prediction, we choose to recompute the properties of the samples taking into account the exact ray cell proportion in the annual ring of each actual sample. This proportion was measured by image analysis (Visilog software) on the initial $x$-ray images. Using this value, new finite element meshes were built, taking care to adjust the width of the single large ray cells so that the REV respects the average ray density.

The new results are listed in Table 3, and Fig. 6 depicts the confrontation of the predicted values with the measured data. Paying particular attention to the exact proportion of ray cells significantly improved the predictive capacity of the model:

- Almost all predicted values fit better than previously the experimental data in both directions.

Table 3 Confrontation of predicted values with experimental data ${ }^{a}$

\begin{tabular}{lllll}
\hline \multirow{2}{*}{ Sample } & \multicolumn{2}{l}{ Experimental data } & \multicolumn{2}{l}{ Predicted values } \\
\cline { 2 - 3 } \cline { 5 - 6 }$\alpha_{\mathrm{R}}(\% / \%)$ & $\alpha_{\mathrm{T}}(\% / \%)$ & & $\alpha_{\mathrm{R}}(\% / \%)$ & $\alpha_{\mathrm{T}}(\% / \%)$ \\
\hline 1 & 0.198 & 0.357 & 0.217 & 0.361 \\
2 & 0.104 & 0.32 & 0.174 & 0.277 \\
3 & 0.258 & 0.44 & 0.250 & 0.416 \\
4 & 0.199 & 0.377 & 0.202 & 0.352 \\
5 & 0.253 & 0.396 & 0.237 & 0.400 \\
6 & 0.155 & 0.29 & 0.194 & 0.282 \\
7 & 0.147 & 0.323 & 0.198 & 0.343 \\
8 & 0.139 & 0.231 & 0.158 & 0.261 \\
9 & 0.183 & 0.366 & 0.230 & 0.376 \\
10 & 0.228 & 0.386 & 0.240 & 0.381 \\
11 & 0.243 & 0.372 & 0.201 & 0.359 \\
12 & 0.191 & 0.382 & 0.258 & 0.423 \\
\hline
\end{tabular}

${ }^{a}$ Second computation: taking care to adjust the width of the single large ray cells in order to match the average ray density.

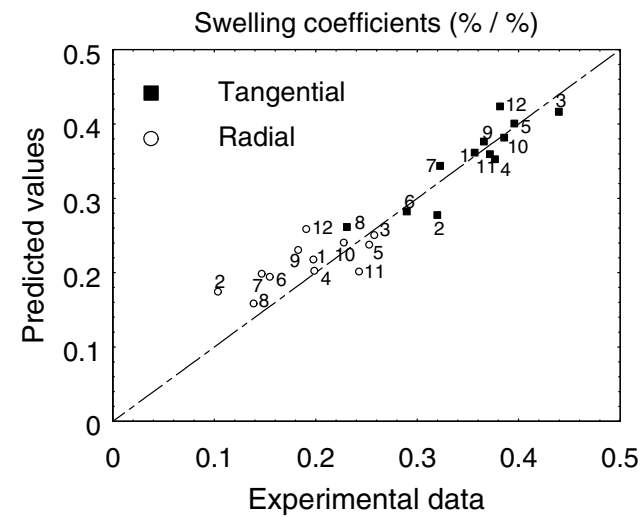

Fig. 6 Accuracy of the predicted values. Twelve samples have been chosen to exhibit a large range of anatomical patterns. They show a large range of swelling behaviour that is well predicted by the cognitive model. The relative average error of the prediction is around $20 \%$ in the radial direction and $5 \%$ in the tangential direction (the error is evaluated according to the Eq. (2))

- In the tangential direction, the average error has been reduced from 9.4 to $5.7 \%$.

- In the radial direction, the improvement is not significant and the error remains clearly worse than for the tangential direction (error: 20.4\%). The prediction still overestimates the experimental data. Note that, even in this case, these relatively poor predictions remain much better than models based on macroscopic parameters (Badel et al. 2006).

Indeed, Fig. 6 exhibits a few points for which the correspondence between the prediction and the experiment is less accurate. Samples 2 and 12, for example, present the worst predictions in the tangential direction. These two points are, in fact, of great interest to go further in the understanding of oak shrinkage.

Sample number 2 exhibits the strangest behaviour. The experimental swelling coefficients are very low in the two transverse directions $\left(\alpha_{\mathrm{R}}=0.104 \% / \%\right.$ and $\left.\alpha_{\mathrm{T}}=0.320 \% / \%\right)$. The model predicts this behaviour well. However, it clearly overestimates the value in the radial direction and underestimates in the tangential direction. Several views were performed using an Environmental Scanning Electronic Microscope (ESEM, Quanta 200). This equipment allows wood to be observed without any coating and without complete desiccation, which dramatically reduces any artefact. The solid blocks from which samples 2 and 12 have originally been sliced were used for the observation. The preparation consisted in a slight superficial planing, which was done using a sledge microtome, in order to produce a clean transverse surface. Figure 7 shows the local cellular structure. This picture depicts the typical conformation of cell walls that buckled (arrows). This state is characteristic of the collapse that can occur during the removal of liquid water. Indeed, when water is removed from wood, capillary forces generate 


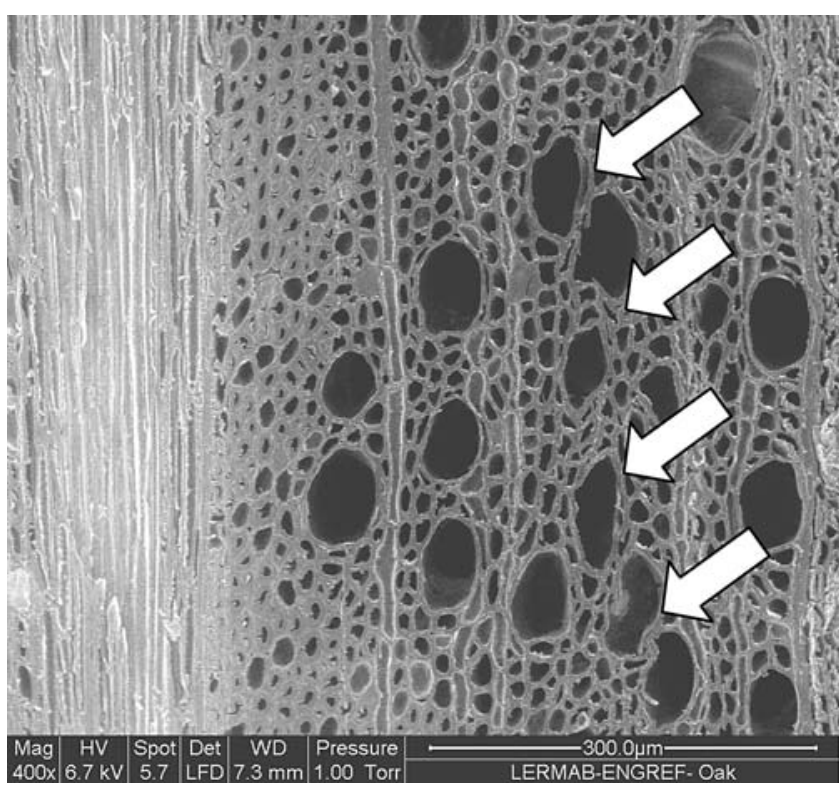

Fig. 7 Local buckling in sample 2. The collapse occurs along radial bands that buckle simultaneously and accentuates the tangential shrinkage. (ESEM, LERMAB by F. Huber)

a depression inside the lumen, and the structure buckles in its weakest areas. This behaviour generates large displacements that are blocked in the radial direction by large ray cells and by the typical alignment of cell wall along the radial direction resulting from cambial activity. In the tangential direction however, the deformation is almost free. This is why collapse usually occurs along radial bands that buckle simultaneously and produces a very large tangential shrinkage. This explains the drastic anisotropic behaviour due to a relatively higher deformation in the tangential direction and the lower deformation in the radial direction found for sample 2 that cannot be predicted by the current model.

The experimental shrinkage of sample 12 is lower than what the model predicted. This is true for both directions (tangential and radial). A microscopic observation proves that a significant proportion of the fibres contains $G$ layers. This anatomical feature is the characteristic of tension wood (Fig. 8). Very little literature exits on the shrinkage behaviour of tension wood in the cross section. Indeed, most works on tension wood are focused on the longitudinal shrinkage. It is usually admitted that the presence of such cells leads to a higher longitudinal deformation than for normal wood. This effect is considered as the consequence of the presence of the gelatinous layer inside the lumen (Clair et al. 2003). For the transversal direction, only Washusen (Washusen and Ilic 2001) observed a positive correlation between the proportion of tension wood and the tangential shrinkage. This hypothesis could explain the relatively high-swelling values (second-highest experimental result in the tangential direction) but does not explain the difference from the model prediction.

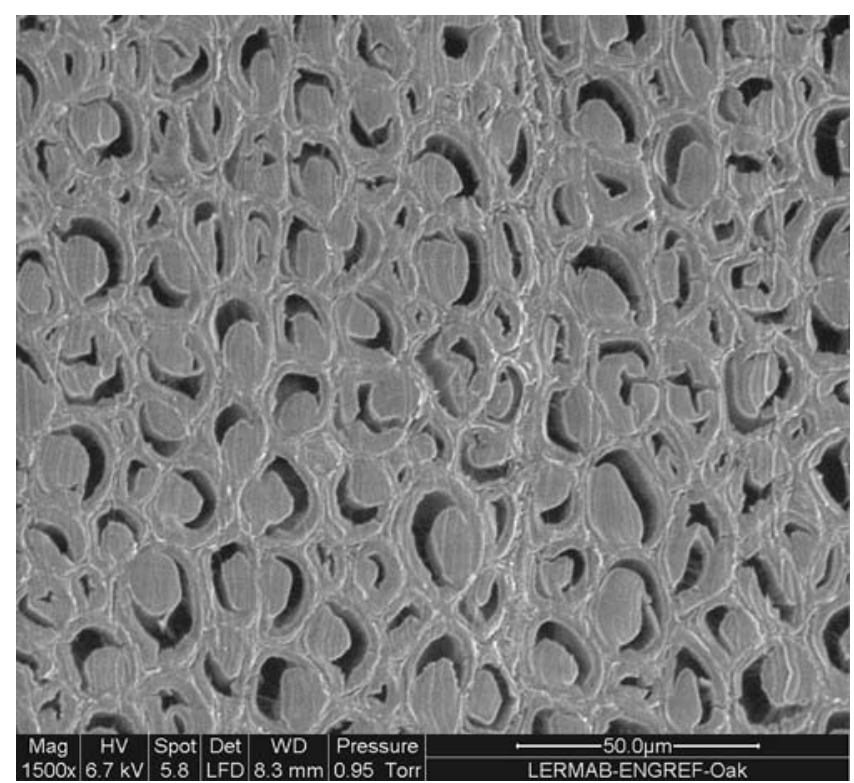

Fig. 8 Microphotograph of sample number 12 (fibre zone in latewood): the shape of the cells and the thickness of the cell walls is typical of tension wood with G-layer.(ESEM, LERMAB by F. Huber)

So far, we have to state the main assumption of this work: the tissue morphology is able to explain a large part of oak variability in terms of shrinkage. For both these particular cases, the sample specificity lies in the variability of the tissue behaviour that is not taken into account in our predictive model. This would be possible, but requires information about the structure at the cell level. This is not integrated into the current computations just because cell features and their effects on the tissue properties would require observations and measurements at a much closer scale.

Coming back at the tissue level, it is interesting to know what is the benefit of accounting for the shape (morphology) of tissue in the prediction of macroscopic properties. For this purpose, the comprehensive model can be compared to a simple model that takes into account only the proportion of the tissues, regardless of the element shapes. This simplified model consists in accounting only for the first term of the right hand side of Eq. (1). Figure 9 depicts the results. At first glance, the results could be qualified as acceptable. However, the computation in the tangential direction is clearly affected by this simplified model. The range of the values and the tendencies seem to be satisfactory placed along the bisector line but the prediction potential decreases drastically and the average error increases from 5 to $18 \%$. For the radial direction, the global error of prediction is not worse than with the complete model (the average error remains around 20\%) but looking at in more detail, the comparison with Fig. 6 shows a tendency along the bisector line that is worse in Fig. 9. This leads to the conclusion that, consistently, this simplified model is able to predict the average property, which is weighted by the tissue proportion, rather than individual values. 


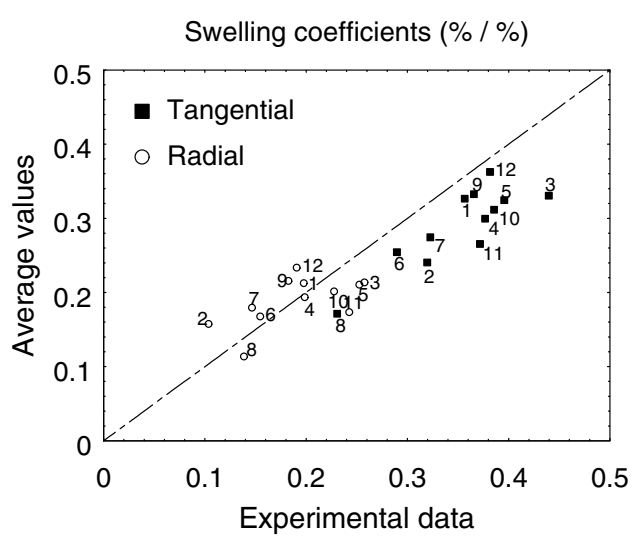

Fig. 9 Values predicted by the simplified model. This model uses the proportion and the properties of each tissue but it does not account for the spatial organisation of these tissues

Table 4 depicts the respective influence of both terms of Eq. (1). This influence of the corrective term is on average around $18 \%$ in the tangential direction and only $12 \%$ in the radial direction. It proves that the spatial organisation of the components plays a more dominant role in the tangential direction for swelling properties than for the radial direction. This can be explained by the significant role of the large ray cells. Their long shape in the radial direction constrains the displacements along this direction while keeping a free displacement of the others tissues in the tangential direction.

\section{Conclusions and perspectives}

For the first time, a morphology-based tool chain has been used to predict the swelling properties of oak wood in the transverse plane. This cognitive model has been confronted with experimental data. The results confirm that the annual ring is the most relevant level of observation to propose a modelling approach for oak wood. The anatomical pattern and the distinction of the four main components of oak (large vessels, large ray cells, fibre zones and parenchyma zones) can explain a great part of the properties, provided their spatial organisation is carefully taken into account. The quality of the model prediction is impressive in the tangential direction for which the error is only about $5 \%$. The results are not so satisfactory in the radial direction, but still are much better than the statistical approaches. No satisfactory explanation can be given to explain the general shortfall in behaviour of the prediction in this direction. The comparison with the simplified model shows that the tangential direction is more sensitive to the change of morphology. The limitation of the performance is linked to special microscopic features like the presence of tension wood or the presence of very dense fibre zones. So, adding the knowledge of the structure at a smaller level (tissue density, etc) to detect such cases would probably increase the quality of the prediction.

The anatomical structure of oak wood, which is the result of the genetic origin and of the growth conditions of the tree, provides enough information to predict the physical properties of the material. This way is, in its spirit, completely different from many other models, which estimate the properties from macroscopic values such as density using statistical correlations. Because all the required data can be obtained using Non-Destructive Techniques, this kind of approach is well adapted to study the behaviour of a single annual ring for which the measurements are not possible (standing trees, old wood, etc). For example, a simple core can be used to characterise the morphology and to predict the swelling behaviour with good accuracy. A first application is
Table 4 Confrontation of predicted values with experimental data ${ }^{a}$

${ }^{a}$ Second computation: taking care to adjust the width of the single large ray cells in order to match the average ray density.

\begin{tabular}{|c|c|c|c|c|c|c|}
\hline \multirow[b]{2}{*}{ Sample } & \multicolumn{2}{|c|}{$\begin{array}{l}\text { Average of the } \\
\text { microscopic properties }\end{array}$} & \multicolumn{4}{|c|}{ Corrective term } \\
\hline & $\overline{\alpha_{\mathrm{R}}(\% / \%)}$ & $\alpha_{\mathrm{T}}(\% / \%)$ & $\overline{\alpha_{\mathrm{R}}(\% / \%)}$ & $\begin{array}{l}\text { Relative influence: } \\
\text { Correc- } \\
\text { tive/macroscopic } \\
(\times 100) \text { Radial }\end{array}$ & $\alpha_{\mathrm{T}}(\% / \%)$ & $\begin{array}{l}\text { Relative influence: } \\
\text { Correc- } \\
\text { tive/macroscopic } \\
(\times 100) \text { Tangential }\end{array}$ \\
\hline 1 & 0.212 & 0.326 & 0.005 & 2.4 & 0.034 & 9.5 \\
\hline 2 & 0.157 & 0.240 & 0.017 & 9.5 & 0.037 & 13.3 \\
\hline 3 & 0.213 & 0.330 & 0.037 & 14.7 & 0.086 & 20.7 \\
\hline 4 & 0.193 & 0.299 & 0.009 & 4.5 & 0.054 & 15.2 \\
\hline 5 & 0.210 & 0.324 & 0.027 & 11.5 & 0.076 & 19.1 \\
\hline 6 & 0.167 & 0.254 & 0.027 & 14.0 & 0.027 & 9.7 \\
\hline 7 & 0.179 & 0.274 & 0.019 & 9.6 & 0.069 & 20.1 \\
\hline 8 & 0.113 & 0.171 & 0.045 & 28.4 & 0.090 & 34.5 \\
\hline 9 & 0.215 & 0.332 & 0.015 & 6.6 & 0.045 & 11.9 \\
\hline 10 & 0.201 & 0.311 & 0.039 & 16.4 & 0.070 & 18.3 \\
\hline 11 & 0.173 & 0.265 & 0.028 & 14.1 & 0.094 & 26.3 \\
\hline 12 & 0.233 & 0.362 & 0.025 & 9.8 & 0.061 & 14.4 \\
\hline
\end{tabular}


in progress in collaboration with ecophysiologists to study the link between growth conditions (especially the climate variations) and wood properties.

Note that the computation time is only a few seconds but the building of a precise finite element mesh is still time consuming.

As a prospect of development for the coming years, the mechanical properties could also be predicted using the same modelling tool chain. Presently, the computation of the mechanical elastic properties is already available but the validation step has to be done.

\section{References}

Badel E (1999) Détermination des propriétés élastiques et du retrait d'un cerne annuel de chêne dans le plan transverse: description de la morphologie, mesures des propriétés microscopiques et calculs d'homogénéisation. PhD dissertation, ENGREF, Nancy

Badel E, Bakour R, Perré P (2006) Investigation of the relationship between anatomical pattern, density and local swelling of oak wood. IAWA 271:55-71

Badel E, Perré P (1999) Détermination des propriétés élastiques d'éléments individuels du plan ligneux du chêne par des essais de traction sur micro-éprouvettes. Ann Forest Sci 56:467-478

Badel E, Perré P (2001) Using a digital X-ray imaging device to measure the swelling coefficients of a group of wood cells. NDT\&E 34:345-353

Badel E, Perré P (2002) Predicting oak wood properties using X-ray inspection: representation, homogenisation and localisation. Part I: Digital X-ray imaging and representation by finite elements. Ann Forest Sci 59:767-776

Bakour R (2003) Influence de l'espèce et de la provenance des deux principaux chênes français (Quercus Robur L.; Quercus Petrea Liebl.) sur la structure anatomique et les propriétés du bois de merrain. PhD dissertation, ENGREF, Nancy

Barber NF (1968) A theoritical model of shrinking wood. Holzforschung 22:97-103

Beismann H, Schweingruber F, Speck T, Korner C (2002) Mechanical properties of spruce and beech wood grown in elevated $\mathrm{CO} 2$. Trees - Struct Funct 168:511-518

Berges L, Dupouey J-L, Franc A (2000) Long-term changes in wood density and radial growth of Quercus petraea Liebl. in northern France since the middle of the nineteenth century. Trees - Struct Funct 147:398-408

Burgert I, Bernasconi A, Niklas KJ, Eckstein (2001) The influence of rays on the transverse elastic anisotropy in green wood of deciduous trees. Holzforschung 55:449-454

Clair B, Ruelle J, Thibaut B (2003) Relationship between growth stress, mechanical-physical properties and proportion of fibre with gelatinous layer in chestnut (castanea sativa mill.). Holzforschung 572:189-195

El Amri F (1987) Contribution à la modélisation élastique anisotrope du matériau bois-feuillus et résineux. PhD dissertation, I.N.P.L., Nancy

Eyono Owoundi R (1992) Modélisation de la rétractibilite du bois en relation avec des paramètres de la structure de l'accroissement annuel et de la position dans l'arbre chez Quercus robur et Q. petraea. PhD dissertation, ENGREF, Nancy
Farruggia F (1998) Détermination du comportement élastique d’un ensemble de fibres de bois à partir de son organisation cellulaire et d'essais mécaniques sous microscope. PhD dissertation, ENGREF, Nancy

Gu H, Zink-Sharp A, Sell J (2001) Hypothesis on the role of cell wall structure in differential transverse shrinkage of wood. Holz als Roh- und Werkstoff 59:436-442

Holmberg S, Persson K, Petersson H (1999) Nonlinear mechanical behaviour and analysis of wood and fibre materials. Comput Struct 724-725:459-480

Kawamura Y (1979) Studies on the properties of rays I. Mokuzai Gakkaishi 25:455-460

Kawamura Y (1984) Studies on the properties of rays II. Mokuzai Gakkaishi 30:201-206

Keller R, Thiercelin F (1975) Influence des gros rayons ligneux sur quelques proprietes du bois de hetre. Ann Forest Sci 32:113-129

Koponen S, Toratti T, Kanerva P (1989) Modelling longitudinal elastic and shrinkage properties of wood. Wood Sci Technol 63:55-63

Le Moguedec G (2000) Modélisation de propriétés de base du bois et de leur variabilité chez le chêne sessile (Quercus petrea Liebl.). Simulation en vue de l'évaluation d'une ressource forestière. $\mathrm{PhD}$ dsissertation, ENGREF, Nancy

Pang S (2002) Predicting anisotropic shringkage of softwood. Part 1: theories. Wood Sci Technol 36:75-91

Perré P (2002). Wood as a multi-scale porous medium: observation, experiment, and modelling. In: First international conference of the European Society for wood mechanics (selected and reviewed papers), EPFL, Lausanne, Switzerland, pp 365-384

Perré P (2005) Meshpore: A software able to apply image-based meshing techniques to anisotropic and heterogeneous porous media. Dry Technol 239-11:1993-2006

Perré P, Badel E (2003) Predicting oak wood properties using X-ray inspection: representation, homogenisation and localisation. Part II: Computation of macroscopic properties and microscopic stress fields. Ann Forest Sci 60:247-257

Salmen L (2004) Micromechanical understanding of the cell-wall structure. Comptes Rendus Biologies 3279-10:873-880

Sanchez-Huber J, Sanchez-Palencia E (1992) Introduction aux méthodes asymptotiques et à l'homogénéisation. Masson, Paris

Seco JIF-G, Barra MRD (1996) Growth rate as a predictor of density and mechanical quality of sawn timber from fast growing species. Holz als Roh- und Werkstoff 543:171-174

Washusen R, Ilic J (2001) Relationship between shrinkage and tension wood from three provenances of Eucalyptus globulus Labill. Holz als Roh- und Werkstoff 59:85-93

Watanabe U, Fujita M, Norimoto M (1998) Transverse shrinkage of coniferous wood cells examined using replica method and power spectrum analysis. Holzforshung 52:200-206

Woodcock S (2002) Wood specific gravity and its radial variations: the many ways to make a tree. Trees-Struct Funct 166:437-443

Yamamoto H (1999) A model of the anisotropic swelling and shrinking process of wood. Part 1. Wood Sci Technol 33:311-325

Yamamoto H, Sassus F, Ninomiya M, Gril J (2001) A model of anisotropic swelling and shrinking process of wood; Part 2. A simulation of shrinking wood. Wood Sci Technol 35:167-181

Zhang SY, Nepveu GFM (1994) Modelling intratree wood shrinkage in european oak by measuring wood density. Forest Prod J 4410:4246 